\title{
Is it possible to predict optimal rocker shoe design using barefoot gait parameters?
}

\author{
Jonathan D Chapman ${ }^{1}$, Stephen J Preece ${ }^{1}$, Christopher J Nester ${ }^{1 *}$, Bjoern Braunstein ${ }^{2}$, Angela Höhne², \\ Gert-Peter Brüggermann² \\ From 4th Congress of the International Foot and Ankle Biomechanics (i-FAB) Community \\ Busan, Korea. 8-11 April 2014
}

\section{Background}

Curved rocker shoes are routinely prescribed for people with diabetes in order reduce in-shoe plantar pressures. However, previous research has shown that different individuals may require different rocker outsole geometries in order to optimise pressure reduction [1,2]. This has led some researchers to suggest that every individual should try a range of possible outsole designs to identify the design which maximises pressure reduction [1]. However, this process may not be feasible in a clinical setting. Given that plantar pressure has been shown to depend on specific gait variables [3], it may be possible to develop an algorithm which could predict an individual's pressure response to a specific rocker outsole design using an input of gait data. Such an algorithm would remove the need to try on a large number of pairs of rocker shoes.

\section{Objective}

To investigate the accuracy of an algorithm developed to predict peak plantar pressure for eight different rocker shoes designs from an input of barefoot gait data.

\section{Methods}

The eight rocker shoes designs spanned different combinations of two design features: rocker angle $\left(15^{\circ}\right.$ or $\left.20^{\circ}\right)$ and apex position (52\%, 57\%, 62\%, 67\% shoe length). A total of $n=76$ patients were recruited into the study and each participant wore each of the eight shoes whilst foot pressure was measured during walking. A gait assessment was then carried out as the participant walked barefoot and a set of gait and anthropometric variables defined as algorithm inputs. A separate algorithm was then developed to predict peak plantar pressure for each of the eight

\footnotetext{
* Correspondence: c.j.nester@salford.ac.uk

'School of Health, Sport and Rehabilitation Sciences, University of Salford, UK Full list of author information is available at the end of the article
}

shoes in three different forefoot regions. In order to develop each algorithm, a regression approach was first used identify a suitable subset of inputs and to estimate the percentage of the variance in peak pressure explained by the inputs. A neural network was then developed and tested to assess predictive power.

\section{Results}

The regression analysis showed that it was possible to explain between $21 \%$ and $47 \%$ of the variance in peak pressure, typically with a set of 3-6 gait/anthropometric variables. However, the predictive power of the neural networks was relatively low, between $24-49 \%$

\section{Conclusion}

Although the results demonstrated clear correlations between groups of gait/anthropometric variables and peak pressure, the predictive power of the algorithm was not high enough for routine use in clinical practice. This may be because additional input variables, such as bony geometry are required to improve algorithm accuracy.

\section{Acknowledgments}

We acknowledge support from the EU framework 7 programme (NMP2-SE2009-229261).

\section{Authors' details}

'School of Health, Sport and Rehabilitation Sciences, University of Salford, UK. ${ }^{2}$ Institute of Biomechanics and Orthopaedics, German Sport University, Cologne, Germany.

Published: 8 April 2014

\section{References}

1. Chapman J, Preece S, Braunstein B, et al: Effect of rocker shoe design features on forefoot plantar pressures in people with and without diabetes. Clin Biomech 2013, 28:679-85. 
2. Morag E, Cavanagh PR: Structural and functional predictors of regional peak pressures under the foot during walking. J Biomech 1999,

32:359-370.

3. van Schie C, Ulbrecht JS, Becker MB, Cavanagh PR: Design criteria for rigid rocker shoes. Foot \& Ankle International 2000, 21:833-844.

doi:10.1186/1757-1146-7-S1-A65

Cite this article as: Chapman et al:: Is it possible to predict optimal

rocker shoe design using barefoot gait parameters? Journal of Foot and Ankle Research 2014 7(Suppl 1):A65.

Submit your next manuscript to BioMed Central and take full advantage of:

- Convenient online submission

- Thorough peer review

- No space constraints or color figure charges

- Immediate publication on acceptance

- Inclusion in PubMed, CAS, Scopus and Google Scholar

- Research which is freely available for redistribution 